\title{
miRNA in Macrophage Development and Function
}

\author{
Sashwati Roy
}

\begin{abstract}
Significance: MicroRNAs (miRNAs) control cellular gene expression via primarily binding to $3^{\prime}$ or $5^{\prime}$ untranslated region of the target transcript leading to translational repression or mRNA degradation. In most cases, miRNAs have been observed to fine-tune the cellular responses and, therefore, act as a rheostat rather than an on/off switch. Transcription factor PU.1 is a master switch that controls monocyte/macrophage development from hematopoietic stem cells. Recent Advances: PU.1 induces a specific set of miRNAs while suppressing the miR17-92 cluster to regulate monocyte/macrophage development. In addition to development, miRNAs tightly control the macrophage polarization continuum from proinflammatory M1 or proreparative M2 by regulating expression of key transcription factors involved in the process of polarization. Critical Issues: miRNAs are intricately involved with fine-tuning fundamental macrophage functions such as phagocytosis, efferocytosis, inflammation, tissue repair, and tumor promotion. Macrophages are secretory cells that participate in intercellular communication by releasing regulatory molecules and microvesicles (MVs). MVs are bilayered lipid membranes packaging a hydrophilic cargo, including proteins and nucleic acids. Macrophage-derived MVs carry functionally active miRNAs that suppress gene expression in target cells via post-transcriptional gene silencing, thus regulating cell function. In summary, miRNAs fine-tune several major facets of macrophage development and function. Such fine-tuning is critical in preventing exaggerated macrophage response to endogenous or exogenous stimuli. Future Directions: A critical role of miRNAs in the regulation of innate immune response and macrophage biology, including development, differentiation, and activation, has emerged. A clear understanding of such regulation on macrophage function remains to be elucidated. Antioxid. Redox Signal. 25, 795-804.
\end{abstract}

Keywords: miRNA, macrophages, wound healing, inflammation, resolution of inflammation, chronic wounds

\section{Introduction}

$\mathbf{H}$ IGH-THROUGHPUT RNA sequencing has unveiled the existence of a large number of noncoding (nc) RNAs in the human genome (57). MicroRNAs (miRNAs), first discovered in 1993 in Caenorhabditis elegans, are evolutionarily conserved 19-25-nt-long ncRNAs of extraordinary functional significance in human health (44). miRNAs are centrally involved in modifying the cellular gene expression response. Gene expression, comprising transcription and translation, is a tightly regulated sophisticated process. Extensive posttranscriptional processing of pre-mRNA is a hallmark of eukaryotic gene expression. This processing provides an additional checkpoint in gene regulation governing the expression of protein, which in turn influences cell function (9). Posttranscriptional control of the $3^{\prime}$ untranslated region ( $3^{\prime}$-UTR) is a key step that determines the rate of translation of mRNA to protein (9).
miRNAs control posttranscriptional gene silencing (PTGS) primarily via binding to $3^{\prime}$ or $5^{\prime}$ UTR of the target transcripts causing translational repression or mRNA degradation. The first evidence of miRNA binding to the $3^{\prime}$-UTR of target mRNA came with the discovery of lin-4 miRNA in C. elegans. Lin-4 was noted to contain sequences that were complementary to $3^{\prime}$-UTR of lin-14 gene, suggesting an antisense RNA-RNA interaction (44). miRNAs are evolutionary conserved across even distant related species, suggesting probable uniformity in the molecular evolution of cellular miRNA gene activity (57). Studies indicate that posttranscriptional regulation of genes by miRNAs is a prevalent phenomenon. According to bioinformatics-based predictions, almost one third of all protein coding genes are posttranscriptionally regulated by miRNAs (21). Recently, a miRNA reporter library study identified functional "miRNAome" of a cell, which represents about $40 \%$ of the total miRNAs with any

Department of Surgery, Davis Heart and Lung Research Institute, Center for Regenerative Medicine and Cell-Based Therapies and Comprehensive Wound Center, The Ohio State University Wexner Medical Center, Columbus, Ohio. 
detectable activity (54). This study raised a significant issue with miRNA profiling, where the number of miRNAs differentially expressed in a cell will be much larger than the actual "functional miRNAome" (54).

Studies during the past two decades have identified and highlighted the significance of miRNAs in a multitude of physiological processes and pathological functions, including development, cell proliferation, hematopoiesis, and cell death. Emerging studies indicate that tissue repair and injury, immune and inflammatory responses are substantially regulated by miRNAs $(16,76,78)$. Cells of the monocyte/ macrophage lineage are critical for mounting and resolving the inflammatory response during tissue injury and repair (17). In this context, this review focuses on miRNAs that control the development, differentiation, and function of monocytes/macrophages by targeting molecules critical in each of these processes.

\section{miRNAs Regulating Development of Myeloid Cells}

Circulating monocytes that originate from adult hematopoietic stem cells (HSCs) are primary precursors of macrophages (88). During homeostasis, HSCs are located in bone marrow (BM) niches. Upon injury, HSCs get mobilized to the spleen and liver (91). Microenvironmental niches in BM dictate the maintenance and differentiation of HSCs (91). miRNAs have been identified as key regulators of HSC renewal and fate (27). Initial evidences pointing toward the significance of miRNAs in HSC regulation came from studies performed on Arsenic resistance protein 2 (Ars2/Asr2) null mice (31). Ars2 is a RNA binding protein that contributes to the delivery of stable miRNA transcripts to the pri-miRNA microprocessor complex, Drosha and DGCR (31). Ars2 null mice suffered from BM failure, suggesting a critical role of miRNAs in HSC renewal and fate (31). Conditional ablation of
Dicer, an RNase III enzyme required for miRNA biogenesis, from the HSC compartment resulted in hematopoietic stem/ progenitor cell apoptosis (32). A subset of miRNAs, including miR-29a, miR-126, miR-155, and miR-125a/b that were specifically enriched in the HSC compartment compared to other cells in the BM (58). Elaborate activities of miR-126, miR130a, and miR-196b were observed in the most primitive HSCs; a loss in such activities was noted with differentiation of HSCs to more mature progenies (27). miR-125a alone was sufficient to augment the stem cell pool specifically targeting proapoptotic protein BAK1 (32). miR-126, abundantly expressed in HSCs, controls expansion of stem cells via targeting the PI3K/AKT/GSK3 $\beta$ pathway (43). Forced expression of miR-126 in HSC impaired cycle progression of HSC, while knockdown of miR-126 resulted in increased HSC proliferation without exhaustion (43). Homozygous ablation of the miR-29a/b- 1 in mice indicated a critical role of miR-29a/b-1 in HSC function by silencing Dnmt3a (33). These studies recognize miR-29a, miR-126, miR-130a miR155 , and $\mathrm{miR}-125 \mathrm{a} / \mathrm{b}$ as key miRNAs that are capable of controlling HSC biology (58) (Fig. 1).

The origin of monocytes from HSC involves differentiation from monoblasts to promonocytes, followed by maturation to monocytes (29). The transcription factor PU.1 facilitates commitment of HSC to lymphoid-myeloid progenitor (LMP) fate via suppression of GATA1 activity (24). The CCAAT/enhancer binding protein (C/EBP) alpha promotes differentiation of LMP to the granulocyte-monocyte progenitor (GMP) stage (24). Increased PU.1 activity favors differentiation of GMP to monocytic lineage (24). miRNAs control multiple steps in the monocyte/macrophage maturation process. PU.1 induces the expression of a subset of four miRs (miR-146a, miR-342, miR-338, and miR-155). This constitutes the initial step in the myeloid cell differentiation/maturation process (28). Forced expression of miR-146a, a negative

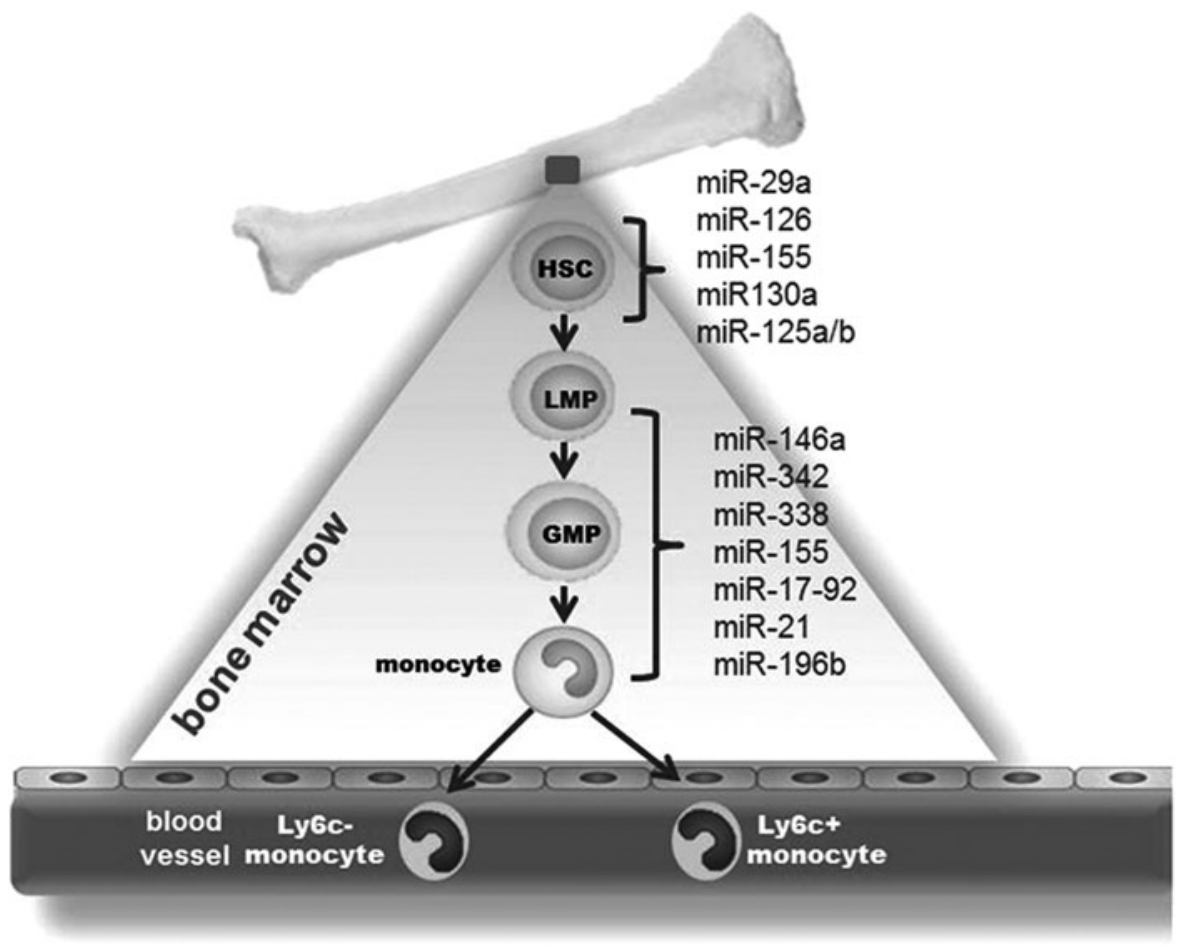

FIG. 1. Involvement of microRNAs (miRNAs) in monocyte/ macrophage development. Circulating monocytes are primarily considered the precursors of macrophages. Monocytes originate from adult hematopoietic stem cells (HSCs) that under favorable conditions differentiate to $\rightarrow$ lymphoid-myeloid progenitor (LMP) $\rightarrow$ granulocyte-monocyte progenitor (GMP) and via multiple steps mature to monocytes. In blood, two populations of monocytes namely Ly6c+ or Ly6c- have been identified in mice. The monocytes then enter to tissues and differentiate to macrophages. 
regulator of innate immune response, was sufficient to drive maturation of stems cells to monocyte/macrophages during adult hematopoiesis (28). In addition to promoting expression of certain miRNA, PU.1 suppresses miR-17p-92 during myeloid differentiation by targeting Egr2 (64). EGR2, in turn, recruits histone demethylase Jarid1b resulting in demethylation of CpG island located at the miR-17-92 promoter (64). The miR17-92 cluster comprises the following six miRNAs: miR-17, miR18a, miR-19a, miR-20a, miR-19b-1, and miR92a. This cluster is present in high levels in early stem and progenitor cells. Expression of the cluster is downregulated upon inception of differentiation to myeloid lineage (64). PU.1 controls a regulatory circuitry involving transcription activation of miR-424 that leads to monocyte differentiation via translational repression of NFI-A (69). A comprehensive list of miRNAs involved in myeloid cell development has been provided by El Gazzar and McCall (20). The studies described above uphold the extraordinary significance of miRNAs in controlling monocyte/macrophage development $(20,28)$.

The relative expression levels of PU.1 and $\mathrm{C} / \mathrm{EBP} \alpha$ dictate the fate of myeloid progenitor cells to monocytic versus granulocytic lineages. Low levels of $\mathrm{C} / \mathrm{EBP} \alpha$ prevent GMP formation, whereas higher levels promote granulopoiesis over monopoiesis (25). $\mathrm{C} / \mathrm{EBP} \alpha$ induces miR-223 resulting in degradation of NFI-A mRNA to promote granulopoiesis (25). Both miR-21 and miR-196b promote the formation of monocytes while suppressing granulopoiesis (89). Interaction of colony stimulating factor-1 (CSF-1) with its CSF-1R promotes differentiation and maturation to monocytic lineage. CSF-1R expression is controlled by Runt-related transcription factor-1 (RUNX1, also known as AML1). miRNAs 175p, 20a, and 106a target the $3^{\prime}$-UTR of Runx 1 and suppress its translation (22). These studies point toward a central role of miRNAs in controlling major stages of monocyte/macrophage development from HSCs. Studies using appropriate conditional knockout/transgenic mice are required to understand specific regulation of these miRNAs in myeloid cell lineage commitment and maturation.

\section{Control of Macrophage Polarization and Activation}

Macrophages are dynamic cells and have the ability to undergo transition through a continuum of phenotypes and activation states primarily based on the microenvironmental milieu. The outstanding significance of microenvironmental cues to direct macrophage polarization at the tissue injury/repair site has been recognized (17). Although contentious, macrophages are broadly classified as M1 and M2 polarization states $(48,53,55)$. M1 macrophages, also known as "classically activated," are induced by cytokines primarily secreted by Th1 cells, including IFN- $\gamma$ and TNF $\alpha$. In addition, granulocytemacrophage colony-stimulating factor (GM-CSF), lipopolysaccharide (LPS), and other Toll-like receptor (TLR) ligands are also known to induce M1 polarization in macrophages. The M1 polarized macrophages support Th1 responses and produce copious amounts of reactive oxygen species (ROS) to help in killing pathogen (48). Conversely, activation of macrophages with Th2 cell factors results in M2 macrophages or "alternatively activated" macrophages. M2 macrophages influence the processes of infection, tissue repair, vascularization, and tumor promotion/invasion. These macrophages are characterized by their high expression of scavenger receptors in addition to high IL-10, VEGF, and MMPs. (48). The microenvironmental signals elicit a transcriptional response that regulates the phenotype and function of the macrophages (42). The signal transducer and activator of transcription 1 (STAT1) and interferon-regulatory factor 5 (IRF5) play a major role in dictating M1 macrophage phenotype (42), whereas, STAT6, peroxisome proliferator-activated receptor- $\gamma$ (PPAR $\gamma)$, and IRF4 direct M2 macrophage polarization (42) (Fig. 2). These transcription factors are directly controlled by specific miRNA (52, 86, 92, 94) (Fig. 2). PU.1, on the contrary, irrespective of polarization, serves as the master transcription factor for maintenance of macrophage identity and differentiation by acting on macrophage-specific enhancers (42).

The JAK/STAT pathway is under miRNA regulation (96). miR-146b suppress the antiviral function in T cells via directly targeting STAT-1 (90). It is not clear if miR-146a also targets STAT-1 in macrophages to control polarization. In a comprehensive study to decipher the role of miRNAs in macrophage polarization, macrophages were subjected to stimuli inducing four different patterns of macrophage activation/polarization (M1, M2a, M2b, and M2c). The changes in miRNA expression profile were elucidated using TaqMan low-density array human miRNA assays (version 2.0; Applied Biosystems) (30). Specific subsets of miRNAs uniquely expressed under four

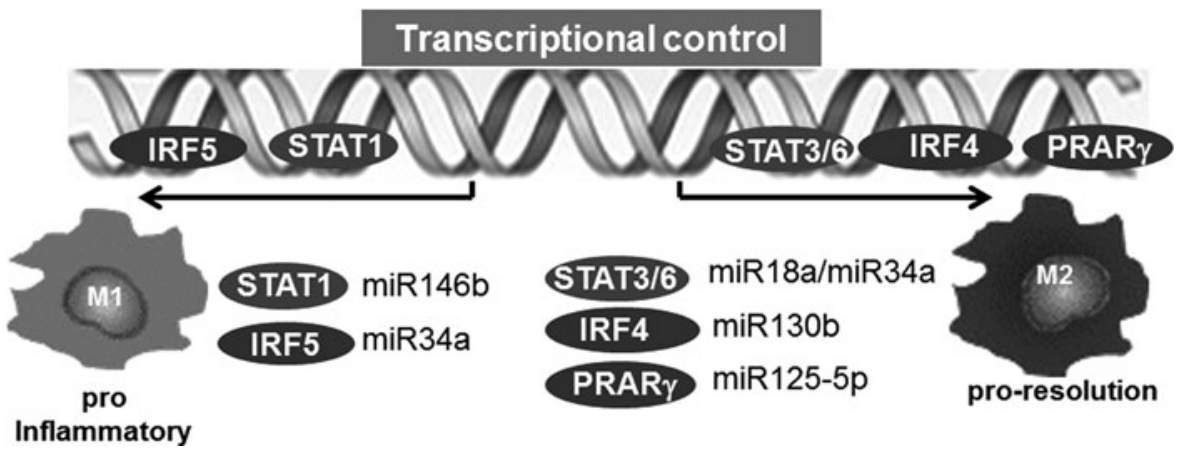

FIG. 2. Transcriptional control of macrophage polarization: role of miRNA. The microenvironmental signals elicit a transcriptional response that regulates the phenotype and function of the macrophages. The signal transducer and activator of transcription 1 (STAT1) and interferon regulatory factor 5 (IRF5) play a major role in dictating M1 macrophage phenotype, whereas, STAT3/STAT6, peroxisome proliferator-activated receptor- $\gamma$ (PPAR $\gamma$ ) and IRF4 direct M2 macrophage polarization. Major reported miRNAs that control these major transcription factors involved in macrophage polarization have been presented. 
conditions of polarization were noted. Specifically, miR-125a-3p and miR-26a-2* in M1 macrophages, while miR-193b, miR27a*, miR-29b-1*, miR-132*, and miR-222* were uniquely expressed in M2b phenotypes (30) (Fig. 3). M2c phenotype did not display any specific change in miRNA expression. Recent studies, including those from our laboratory, demonstrate a critical role of miR-21 in macrophage polarization (8, 16). We reported that miR-21 is central in efferocytosis (engulfment of apoptotic cells)-mediated change in macrophage from a proinflammatory (M1) to proresolving (M2) phenotype (16). In line with this observation, activation of CSF-1R by its ligands CSF-1 and IL-34 plays a major role in macrophage development and differentiation. The molecular signaling elicited by CSF-1R pathway has been shown to regulate macrophage polarization via $\mathrm{PI} 3 \mathrm{~K} \rightarrow \mathrm{ERK} \rightarrow \mathrm{NF} \kappa \mathrm{B}$ and activation miR-21. Inhibition of miR-21 directed macrophage toward the $\mathrm{M} 1$ phenotype, suggesting that sufficient miR-21 in macrophages is essential for their M2 polarization (8). A central role of miR-33 in regulation of cellular lipid metabolism by repressing genes involved in cholesterol efflux, and fatty acid oxidation, has been recognized (39). A shift of macrophage metabolism toward glycolysis promotes M1 or proinflammatory phenotype (26). miR-33 was recently reported to promote macrophages toward M2 phenotype via targeting AMP-activated protein kinase, a key player in intracellular energy equilibrium (61).

\section{Regulation of Monocyte/Macrophage Function}

Macrophages/monocytes are implicated in regulation of a multitude of biological processes, including inflammation and phagocytosis $(53,55)$. To maintain focus, we limit discussion to the roles of miRNAs in regulation of key functions of monocyte/ macrophages related to inflammation and tissue repair (Fig. 4).

\section{Inflammation}

Inflammation is a dynamic process that is elicited following injury/infection and other external stimuli with the objective to repair and restore homeostasis (68). Macrophages are key cells of the innate immune system, an evolutionarily conserved form of host defense against infection (36). miRNAs control multiple regulatory checkpoints to fine-tune macrophage inflammatory response $(71,72)$. TLR and related downstream signaling cascade pathways are important detection mechanisms that enable the initial steps of the inflammatory cascade. The first evidence recognizing inflammation-sensitive miRNAs in macrophages was provided using miRNA expression profiling in endotoxin-treated murine macrophages (84). Of the $200 \mathrm{miRNAs}$ investigated, miR-146a/b, miR132, and miR-155 were identified as LPS-responsive miRNAs (84). Promoter analysis studies recognized miR-146a as a NF- $\kappa$ B-inducible miRNA (84). In addition, the study also identified binding sites for miR-146a/b at the $3^{\prime}$-UTRs of the TNF receptor-associated factor 6 (TRAF6) and IL-1 receptorassociated kinase 1 (IRAK1) genes, suggesting these targets may be subjected to PTGS by miR146a/b (84). A key function of miR-146 controlling TLR and cytokine signaling via a negative feedback regulation loop was proposed (84). This study was instrumental in highlighting the significance of inflammation-sensitive miRNAs in macrophages. An induction of miR-155 in mouse macrophages exposed to inflammatory mediators polyriboinosinic:polyribocytidylic acid or the cytokine IFN- $\beta$ was identified (59). miR-155 tightly controlled the expression of SHIP1 and SOCS1, both critical regulators of the inflammatory response in macrophages (59). Bala et al. reported that increased miR-155 levels contribute to alcohol-induced elevation in TNF- $\alpha$ production (4). miRNAs let-7i, miR-145, and miR-346 were shown to regulate TLR signaling. Of these, only let-7i inversely correlated with TLR signaling and immune response $(60,74)$. $\mathrm{NF} \kappa \mathrm{B}$ is a master transcription factor that regulates the expression of proinflammatory cytokines such as TNF- $\alpha$, IL- $1 \beta$, IL- 6 , and IL-8 in macrophages $(37,38)$. miR-146, one of the first miRNA identified to be involved in the $\mathrm{NF} \kappa \mathrm{B}$ activation pathway, constitutes a negative feedback loop where $\mathrm{NF} \kappa \mathrm{B}$ activates miR-146, which in turn suppresses $\mathrm{NF} \kappa \mathrm{B}$ signaling by directly targeting TRAF6 and IRAK1 (84). Conversely, miR-181b indirectly regulated $\mathrm{NF} \kappa \mathrm{B}$ in a positive feedback

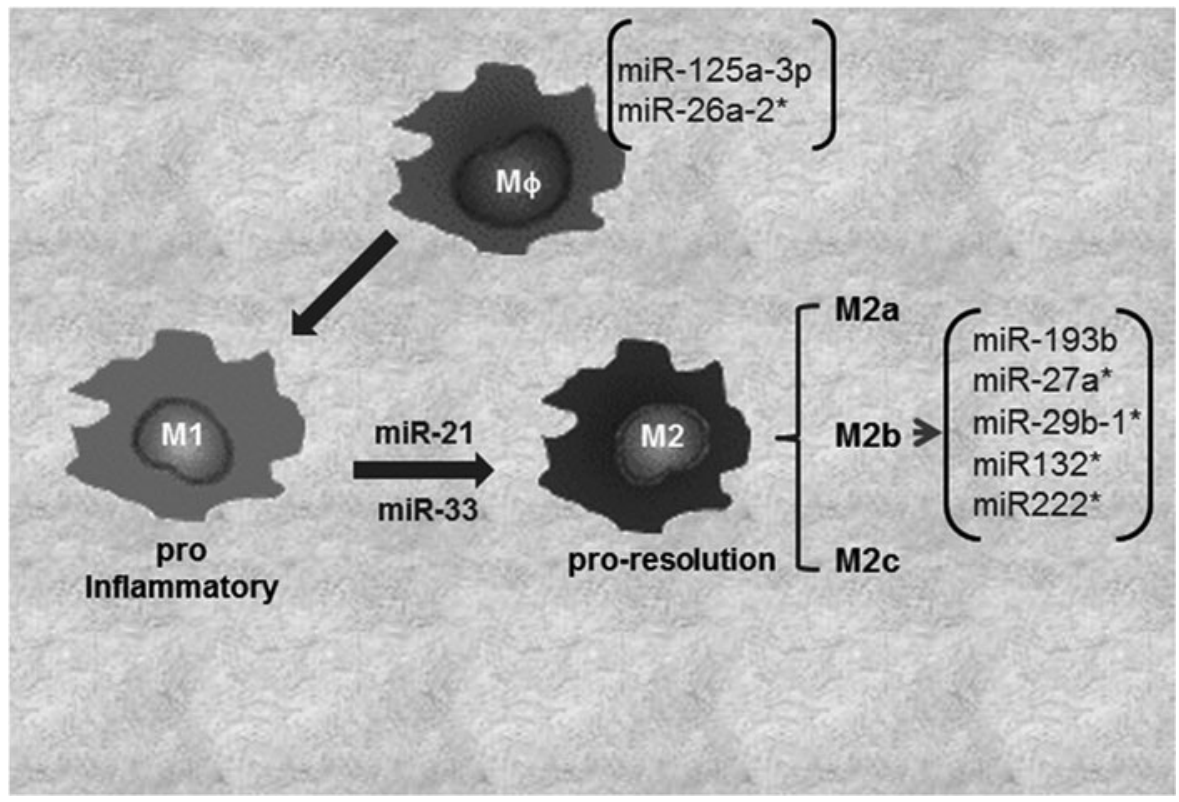

FIG. 3. Involvement of miRNAs in macrophage polarization. In tissues based on microenvironment, the macrophages get polarized to M1 or M2 (M2a, M2b, or M2c subtypes). Major miRNAs involved/expressed in macrophage polarization have been shown. 
FIG. 4. miRNAs in macrophage function and intercellular communication. Macrophages are closely involved with a number of biological functions. Major miRNA that has been identified with each of the macrophage-mediated key process has been presented.

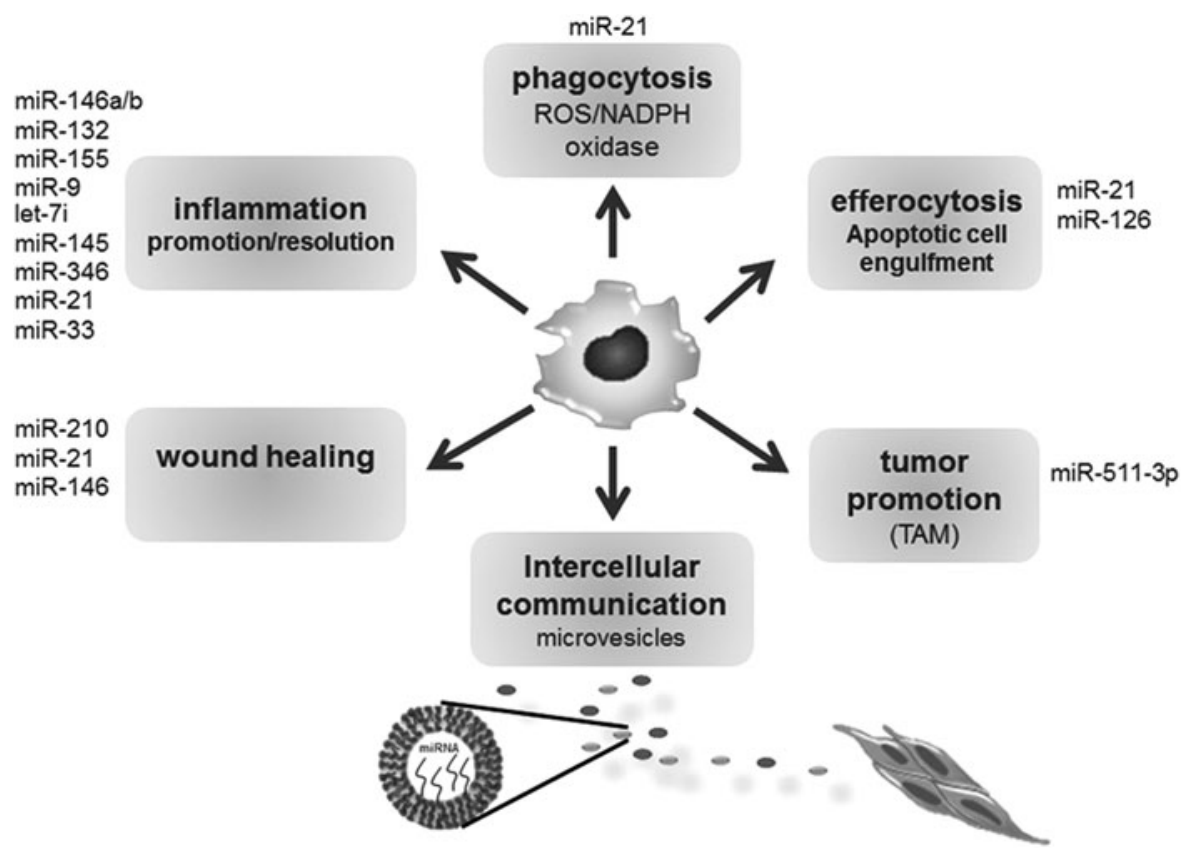

loop that included NF $\kappa \mathrm{B} \rightarrow$ IL- $6 \rightarrow$ STAT3 $\rightarrow$ miR-181b $\rightarrow \mathrm{CYLD} \rightarrow \mathrm{NF} \kappa \mathrm{B}(46)$. NF $\kappa \mathrm{B}$-dependent reporter assay screening of several hundred miRNA genes identified miR$301 \mathrm{a}$ as one of the most effective activators of $\mathrm{NF} \kappa \mathrm{B}$ by repressing $\mathrm{NF} \kappa \mathrm{B}$ repressing factor (46) (Fig. 5). miR-9 has been linked with innate immune response; the expression of this miRNA contributes to a negative feedback loop in the $\mathrm{NF} \kappa \mathrm{B}$ pathway, where miR-9 is activated by TLR $4 \rightarrow \mathrm{NF} \kappa \mathrm{B}$ in human PMNs and monocytes target $\mathrm{NF} \kappa \mathrm{B}$ subunit $\mathrm{p} 50$ (6). The studies discussed above clearly indicate that miRNAs fine-tune the inflammatory response by controlling major pathways such as TLR and NF $\kappa \mathrm{B}$. miRNA control of other major transcription factors implicated with inflammatory response has been highlighted $(5,10,14,34,45,56,62)$ (Fig. 5). Such control by miRNA is likely to prevent an exaggerated inflammatory response.
FIG. 5. miRNAs control the expression of major transcription factors that govern the inflammation response. Gene expression in inflammation response is under tight control of a number of transcription factors, including $\mathrm{NF}-\kappa \mathrm{B}$, activator protein-1 (AP-1), hypoxia inducible factor (HIF-1 $\alpha$ ), and JAK/STAT. The expression of these transcription factors is regulated by miRNA, often in a regulatory feedback loop. In addition, shown are the miRNA, the expression of which is regulated by these transcription factors.

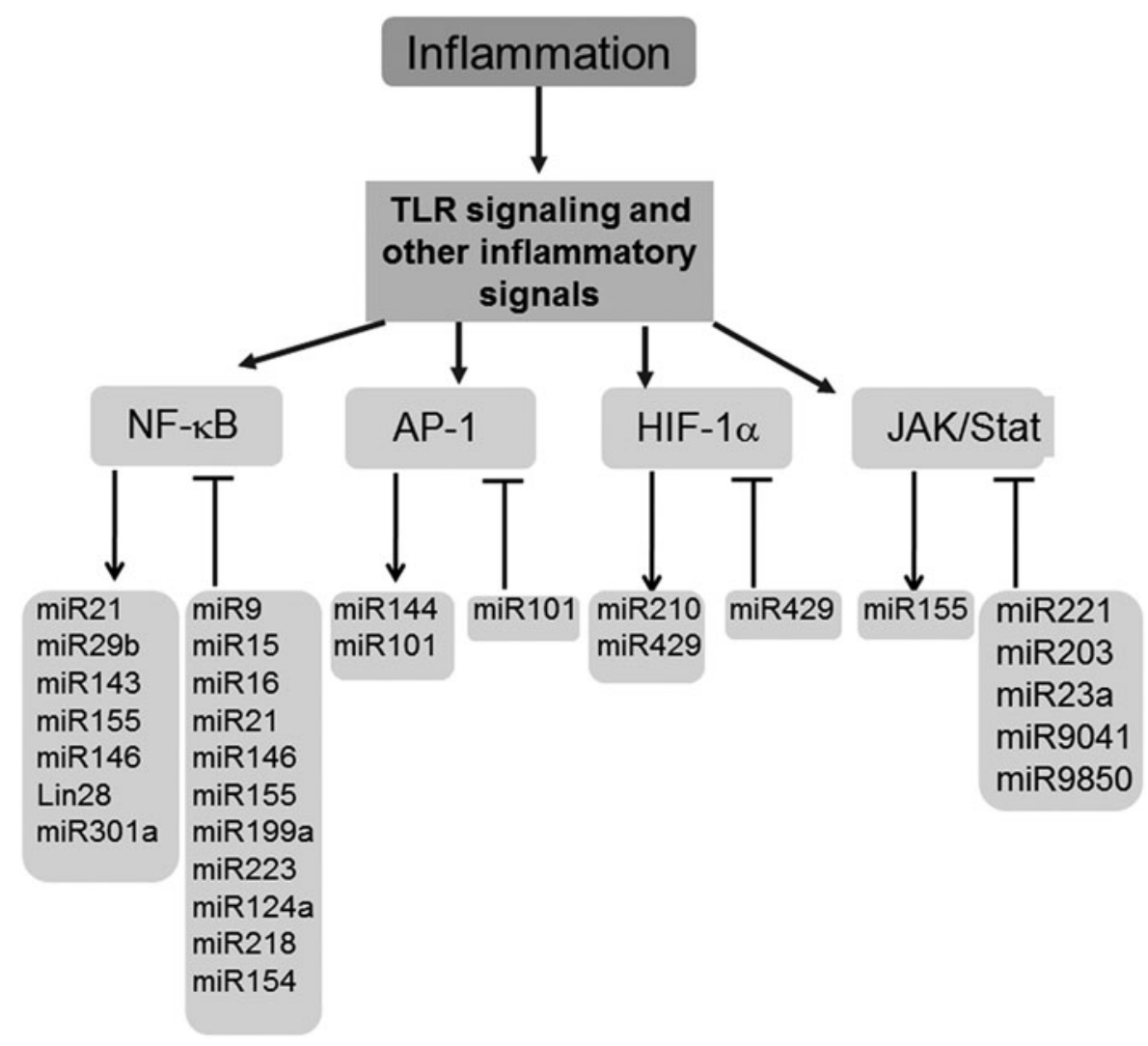




\section{ROS production and function}

In response to inflammation, phagocytosis, or environmental stimuli, macrophages produce copious amounts of ROS by a process known as "respiratory burst" $(2,63)$. NADPH oxidases are primarily responsible for the "respiratory burst" action in cells of myeloid origin (3). NAPDH oxidase is a multisubunit complex that comprises membrane-bound cytochrome component, that is, gp91phox (phagocyte oxidase) and cytoplasmic components, including p47phox, p67phox, and p40phox, and rac $(23,63,75)$. Upon activation, the cytosolic subunits translocate to the membrane-bound gp91. In 2008, our laboratory reported first evidence demonstrating that the ratelimiting p47phox subunit of NADPH oxidase is a target for miRNA (80). Global lowering of cellular miRNAs by knocking down Dicer, a key enzyme of miRNA biogenesis, resulted in decreased production of inducible ROS (80). Recently, a cross talk between ROS and miR-451 was identified using BM-derived macrophages from $\mathrm{p} 47$ phox null mice (65). Furthermore, miR-21 via targeting PDCD4-AP-1 pathway was observed to regulate $\mathrm{H}_{2} \mathrm{O}_{2}$-dependent responses in smooth muscle vascular cell injury model. Using a global profiling approach, miRNA signature in response to oxidative stress such as ionizing radiation and $\mathrm{H}_{2} \mathrm{O}_{2}$ was determined (81). The pathways underlying oxidant-induced miRNA expression remain to be characterized.

\section{Efferocytosis}

Macrophages are responsible for cleaning up host tissue of invading pathogens as well as dead/dying cell debris. The process of engulfment of dead/dying cells by macrophages is referred to as "efferocytosis" (19). Efferocytosis is well known to play a central role in the resolution of inflammation (70). Despite the resemblance between the processes of efferocytosis and phagocytosis, the two processes are clearly distinct with respect to receptors and ligands involved $(67,87)$. Efferocytosis initiates signaling events involving two main complexes, (i) CrkII/ELMO/Dock180 or (ii) ABCA1/GULP (40). Activation of either complex leads to activation of Rac1, which initiates cytoskeletal rearrangement and subsequent engulfment of apoptotic cells (40). miRNAs have been implicated in the signaling cascade involving efferocytosis-induced resolution of inflammation, more specifically the change in macrophage phenotype following efferocytosis (16). Engulfment of apoptotic cells by macrophages dampened proinflammatory response and promoted an anti-inflammatory milieu by secretion of cytokines such as IL-10. Studies from our laboratory identified that in macrophages miR-21 can be induced by efferocytosis. Elevated macrophage miR-21 supported efferocytosis and silenced target genes PTEN and PDCD4, which in turn upregulated IL-10 and suppressed $\mathrm{TNF} \alpha$ production, respectively, accounting for a net antiinflammatory M2-like phenotype observed in postefferocytotic macrophages (16). CrkII, a protein of the efferocytosis engulfment complex, has also been proposed to be a direct target of miR-126, indicating a potential regulation of miRNA at an upstream efferocytosis-mediated signaling pathway (15).

\section{Wound healing}

Wound healing is a well-orchestrated reparative event that occurs in response to injury and its microenvironment (49).
Macrophages infiltrating the wound site postinjury are often termed as wound macrophages (17). Wound macrophages are essential for repair $(17,50,51)$. Work from our laboratory has focused on developing the significance of miRNAs in controlling molecular mechanisms that regulates wound healing (7, 11-13, 76, 77, 79, 80). Here, we limited discussion to those miRNAs that directly regulate macrophage function in wound healing. miR-21 was identified by us recently as a major negative regulator of LPS-induced inflammatory response in wound macrophages (16). miR-146a, an inflammationsensitive miRNA, was significantly low in diabetic wounds (93). Such decreased miR-146a levels caused upregulation of proinflammatory target genes (93). The study did not, however, identify a role of wound macrophages in miR-146 dysfunction in diabetic ulcers. The studies to explore the significance of miRNAs in wound macrophage activation and function have just begun. Further studies investigating significance of miRNAs in wound macrophage activation and function are required to understand the mechanisms underlying the critical role of macrophages in wound healing.

\section{Tumor-associated macrophages}

Macrophages located in tumor stroma are referred to as tumor-associated macrophages (TAMs) (47). These macrophages primarily display M2 phenotype and modify inflammation, promote angiogenesis, matrix remodeling, and tumor cell migration/invasion, thereby suppressing antitumor immunity $(47,82)$. The presence of a higher number of TAMs is associated with tumor progression and poor patient prognosis (47). Cancer-related studies suggest the involvement of miRNAs in modulating response to TAM by directly acting on these macrophages and the precursors of these cells, including HSCs (82). In mouse models, a specific subset of TAMs that displays high expression of the mannose receptor (MRC1/CD206) and attenuated CD11c expression has been identified with high proangiogenic and tumorigenic activities (83). miR-511-3p, an intronic miRNA, is encoded by both mouse and human MRC1 genes (83). Using reporter vector bioassay, miR-511-3p was noted to show high expression and activity in CD206 ${ }^{+}$TAMs (83). By targeting CD206 (MRC1), miRNA-511-3p plays a critical role as gatekeepers of the protumorigenic activity of TAMs. Detailed studies investigating relevance of miRNAs in TAM subset phenotype and their influence on the activity of TAM are warranted.

\section{Macrophage Intercellular Communications Via Extravesicular Release}

Macrophages are secretory cells that control specific cellular processes via intercellular communication. Extracellular membrane vesicles (EVs) function as shuttles between cells for delivery of cargo such as proteins; mRNAs and miRNAs have emerged as major mediators of intercellular communication (66). Exosomes, microvesicle (MVs), and apoptotic bodies are three broad categories of EVs that are released by a number of cells, including macrophages (95). Exosomes are vesicles of endosomal origin that originate by inward budding and are between 40 and $100 \mathrm{~nm}$ in diameter (85). However, the MVs are released from plasma membranes as a result of outward budding and fission $(85,95)$. Macrophages secrete both MVs and exosomes that carry cargo, including proteins; mRNA and miRNA are for intercellular communication (41). 
In peripheral blood, the majority of circulating microvesicles originate from platelets, while monocytes/macrophages contribute the second most abundant population of circulating MVs in blood (35). Macrophage-derived MVs have been demonstrated to carry functionally active miR-223 that subsequently induces macrophage differentiation and is an important contributor to the innate immune response (35). Another example of transferring functionally active miRNAs was provided by an observation where human macrophages, via gap junctions, transferred miR-142 and miR-223 to hepatocarcinoma cells (HCCs) (1). Such transfer of miRNAs resulted in PTGS of target proteins, that is, stathmin-1 and insulin-like growth factor-1 receptor in HCC, suggesting that such transfer is not just a passive process, rather it actively regulates functions in the acceptor cell. Another example of active transfer has been recently reported where monocytes exposed to alcohol communicated with naive monocyte via miR-27a cargo transferred from EVs (73). Transfer of miRNA resulted in naive macrophages to polarize to M2 macrophages (73). Taken together, macrophage-derived exosome and MV-mediated transfer of miRNAs add a novel dimension to how macrophages modify inflammatory responses and other cellular activities.

\section{Conclusion}

During the last decade, we have witnessed an unprecedented growth in understanding of miRNAs in health and disease. In most cases, miRNAs have been observed to fine-tune cellular responses and, therefore, act as a rheostat rather than an on/off switch. A critical role of miRNAs in the regulation of innate immune response and macrophage biology, including development, differentiation, and activation, has emerged. miRNA expression and activity are evolutionarily conserved and highly cell specific. Increased macrophage-specific knockout/transgenic studies will clarify the significance of these tiny molecular rheostats on development, differentiation, and activity of these cells in regulation of biological responses. Such information will be critical in developing miRNA-directed therapies. In summary, miRNAs fine-tune numerous facets of macrophage development and function. Such fine-tuning is critical in preventing exaggerated macrophage response to endogenous or exogenous stimuli.

\section{Acknowledgments}

Wound healing research in the author's laboratory is funded by NIDDK R01 DK076566, NIGMS RO1 GM108014, GM069589, GM 077185, NINR NR013898, \& NR015676.

\section{References}

1. Aucher A, Rudnicka D, and Davis DM. MicroRNAs transfer from human macrophages to hepato-carcinoma cells and inhibit proliferation. J Immunol 191: 6250-6260, 2013.

2. Babior BM. The respiratory burst of phagocytes. $J$ Clin Invest 73: 599-601, 1984.

3. Babior BM. The respiratory burst oxidase. Hematol Oncol Clin North Am 2: 201-212, 1988.

4. Bala S, Marcos M, Kodys K, Csak T, Catalano D, Mandrekar P, and Szabo G. Up-regulation of microRNA-155 in macrophages contributes to increased tumor necrosis factor \{alpha\} (TNF $\{$ alpha $\}$ ) production via increased mRNA half-life in alcoholic liver disease. J Biol Chem 286: 14361444, 2011.

5. Bartoszewska S, Kochan K, Piotrowski A, Kamysz W, Ochocka RJ, Collawn JF, and Bartoszewski R. The hypoxia-inducible miR-429 regulates hypoxia-inducible factor-1alpha expression in human endothelial cells through a negative feedback loop. FASEB J 29: 1467-1479, 2015.

6. Bazzoni F, Rossato M, Fabbri M, Gaudiosi D, Mirolo M, Mori L, Tamassia N, Mantovani A, Cassatella MA, and Locati M. Induction and regulatory function of miR-9 in human monocytes and neutrophils exposed to proinflammatory signals. Proc Natl Acad Sci U S A 106: 5282-5287, 2009.

7. Biswas S, Roy S, Banerjee J, Hussain SR, Khanna S, Meenakshisundaram G, Kuppusamy P, Friedman A, and Sen CK. Hypoxia inducible microRNA 210 attenuates keratinocyte proliferation and impairs closure in a murine model of ischemic wounds. Proc Natl Acad Sci U S A 107: 6976-6981, 2010.

8. Caescu CI, Guo X, Tesfa L, Bhagat TD, Verma A, Zheng $\mathrm{D}$, and Stanley ER. Colony stimulating factor-1 receptor signaling networks inhibit mouse macrophage inflammatory responses by induction of microRNA-21. Blood 125 : e1-e13, 2015.

9. Carpenter S, Aiello D, Atianand MK, Ricci EP, Gandhi P, Hall LL, Byron M, Monks B, Henry-Bezy M, Lawrence JB, O’Neill LA, Moore MJ, Caffrey DR, and Fitzgerald KA. A long noncoding RNA mediates both activation and repression of immune response genes. Science 341: 789-792, 2013.

10. Chan YC, Banerjee J, Choi SY, and Sen CK. miR-210: the master hypoxamir. Microcirculation 19: 215-223, 2012.

11. Chan YC, Khanna S, Roy S, and Sen CK. miR-200b targets Ets-1 and is down-regulated by hypoxia to induce angiogenic response of endothelial cells. J Biol Chem 286: 20472056, 2011.

12. Chan YC, Roy S, Huang Y, Khanna S, and Sen CK. The microRNA miR-199a-5p down-regulation switches on wound angiogenesis by derepressing the v-ets erythroblastosis virus E26 oncogene homolog 1-matrix metalloproteinase-1 pathway. J Biol Chem 287: 41032-41043, 2012.

13. Chan YC, Roy S, Khanna S, and Sen CK. Downregulation of endothelial microRNA-200b supports cutaneous wound angiogenesis by desilencing GATA binding protein 2 and vascular endothelial growth factor receptor 2. Arterioscler Thromb Vasc Biol 32: 1372-1382, 2012.

14. Cheng C, Li W, Zhang Z, Yoshimura S, Hao Q, Zhang C, and Wang Z. MicroRNA-144 is regulated by activator protein-1 (AP-1) and decreases expression of Alzheimer disease-related a disintegrin and metalloprotease 10 (ADAM10). J Biol Chem 288: 13748-13761, 2013.

15. Crawford M, Brawner E, Batte K, Yu L, Hunter MG, Otterson GA, Nuovo G, Marsh CB, and Nana-Sinkam SP. MicroRNA126 inhibits invasion in non-small cell lung carcinoma cell lines. Biochem Biophys Res Commun 373: 607-612, 2008.

16. Das A, Ganesh K, Khanna S, Sen CK, and Roy S. Engulfment of apoptotic cells by macrophages: a role of MicroRNA-21 in the resolution of wound inflammation. J Immunol 192: 1120-1129, 2014.

17. Das A, Sinha M, Datta S, Abas M, Chaffee S, Sen CK, and Roy S. Monocyte and macrophage plasticity in tissue repair and regeneration. Am J Pathol, 185: 2596-2606, 2015.

18. This reference has been deleted.

19. deCathelineau AM and Henson PM. The final step in programmed cell death: phagocytes carry apoptotic cells to the grave. Essays Biochem 39: 105-117, 2003. 
20. El Gazzar M and McCall CE. MicroRNAs regulatory networks in myeloid lineage development and differentiation: regulators of the regulators. Immunol Cell Biol 90: 587-593, 2012.

21. Filipowicz W, Bhattacharyya SN, and Sonenberg N. Mechanisms of post-transcriptional regulation by microRNAs: are the answers in sight? Nat Rev Genet 9: 102-114, 2008.

22. Fontana L, Pelosi E, Greco P, Racanicchi S, Testa U, Liuzzi F, Croce CM, Brunetti E, Grignani F, and Peschle C. MicroRNAs 17-5p-20a-106a control monocytopoiesis through AML1 targeting and M-CSF receptor upregulation. Nat Cell Biol 9: 775-787, 2007.

23. Forman HJ and Torres M. Reactive oxygen species and cell signaling: respiratory burst in macrophage signaling. Am J Respir Crit Care Med 166: S4-S8, 2002.

24. Friedman AD. Transcriptional control of granulocyte and monocyte development. Oncogene 26: 6816-6828, 2007.

25. Friedman AD. C/EBPalpha in normal and malignant myelopoiesis. Int J Hematol 101: 330-341, 2015.

26. Galván-Peña S and O'Neill LAJ. Metabolic reprograming in macrophage polarization. Front Immunol 5: 1-6, 2014.

27. Gentner B, Visigalli I, Hiramatsu H, Lechman E, Ungari S, Giustacchini A, Schira G, Amendola M, Quattrini A, Martino S, Orlacchio A, Dick JE, Biffi A, and Naldini L. Identification of hematopoietic stem cell-specific miRNAs enables gene therapy of globoid cell leukodystrophy. Sci Transl Med 2: 58ra84, 2010.

28. Ghani S, Riemke P, Schonheit J, Lenze D, Stumm J, Hoogenkamp M, Lagendijk A, Heinz S, Bonifer C, Bakkers J, Abdelilah-Seyfried S, Hummel M, and Rosenbauer F. Macrophage development from HSCs requires PU.1-coordinated microRNA expression. Blood 118: 2275-2284, 2011.

29. Gordon S and Taylor PR. Monocyte and macrophage heterogeneity. Nat Rev Immunol 5: 953-964, 2005.

30. Graff JW, Dickson AM, Clay G, McCaffrey AP, and Wilson ME. Identifying functional microRNAs in macrophages with polarized phenotypes. J Biol Chem 287: 21816-21825, 2012.

31. Gruber JJ, Zatechka DS, Sabin LR, Yong J, Lum JJ, Kong M, Zong WX, Zhang Z, Lau CK, Rawlings J, Cherry S, Ihle JN, Dreyfuss G, and Thompson CB. Ars2 links the nuclear cap-binding complex to RNA interference and cell proliferation. Cell 138: 328-339, 2009.

32. Guo S, Lu J, Schlanger R, Zhang H, Wang JY, Fox MC, Purton LE, Fleming HH, Cobb B, Merkenschlager M, Golub TR, and Scadden DT. MicroRNA miR-125a controls hematopoietic stem cell number. Proc Natl Acad Sci U S A 107: 14229-14234, 2010.

33. Hu W, Dooley J, Chung SS, Chandramohan D, Cimmino L, Mukherjee S, Mason CE, de Strooper B, Liston A, and Park CY. miR-29a maintains mouse hematopoietic stem cell selfrenewal by regulating Dnmt3a. Blood 125: 2206-2216, 2015.

34. Huang Y, Wang W, and Ren Q. Two host microRNAs influence WSSV replication via STAT gene regulation. Sci Rep 6: 23643, 2016.

35. Ismail N, Wang Y, Dakhlallah D, Moldovan L, Agarwal K, Batte K, Shah P, Wisler J, Eubank TD, Tridandapani S, Paulaitis ME, Piper MG, and Marsh CB. Macrophage microvesicles induce macrophage differentiation and miR-223 transfer. Blood 121: 984-995, 2013.

36. Janeway CA, Jr. and Medzhitov R. Innate immune recognition. Annu Rev Immunol 20: 197-216, 2002.

37. Karin M, Cao Y, Greten FR, and Li ZW. NF-kappaB in cancer: from innocent bystander to major culprit. Nat Rev Cancer 2: 301-310, 2002.
38. Karin M and Greten FR. NF-kappaB: linking inflammation and immunity to cancer development and progression. Nat Rev Immunol 5: 749-759, 2005.

39. Karunakaran D, Thrush AB, Nguyen MA, Richards L, Geoffrion M, Singaravelu R, Ramphos E, Shangari P, Ouimet M, Pezacki JP, Moore KJ, Perisic L, Maegdefessel L, Hedin U, Harper ME, and Rayner KJ. Macrophage mitochondrial energy status regulates cholesterol efflux and is enhanced by anti-miR33 in atherosclerosis. Circ Res 117: 266-278, 2015.

40. Korns D, Frasch SC, Fernandez-Boyanapalli R, Henson PM, and Bratton DL. Modulation of macrophage efferocytosis in inflammation. Front Immunol 2: 57, 2011.

41. Lakkaraju A and Rodriguez-Boulan E. Itinerant exosomes: emerging roles in cell and tissue polarity. Trends Cell Biol 18: 199-209, 2008.

42. Lawrence $\mathrm{T}$ and Natoli $\mathrm{G}$. Transcriptional regulation of macrophage polarization: enabling diversity with identity. Nat Rev Immunol 11: 750-761, 2011.

43. Lechman ER, Gentner B, van Galen P, Giustacchini A, Saini M, Boccalatte FE, Hiramatsu H, Restuccia U, Bachi A, Voisin V, Bader GD, Dick JE, and Naldini L. Attenuation of miR-126 activity expands HSC in vivo without exhaustion. Cell Stem Cell 11: 799-811, 2012.

44. Lee RC, Feinbaum RL, and Ambros V. The C. elegans heterochronic gene lin-4 encodes small RNAs with antisense complementarity to lin-14. Cell 75: 843-854, 1993.

45. Liu JJ, Lin XJ, Yang XJ, Zhou L, He S, Zhuang SM, and Yang J. A novel AP-1/miR-101 regulatory feedback loop and its implication in the migration and invasion of hepatoma cells. Nucleic Acids Res 42: 12041-12051, 2014.

46. Ma X, Becker Buscaglia LE, Barker JR, and Li Y. MicroRNAs in NF-kappaB signaling. J Mol Cell Biol 3: 159-166, 2011.

47. Mantovani A, Schioppa T, Porta C, Allavena P, and Sica A. Role of tumor-associated macrophages in tumor progression and invasion. Cancer Metastasis Rev 25: 315-322, 2006.

48. Mantovani A, Sozzani S, Locati M, Allavena P, and Sica A. Macrophage polarization: tumor-associated macrophages as a paradigm for polarized M2 mononuclear phagocytes. Trends Immunol 23: 549-555, 2002.

49. Martin P. Wound healing - aiming for perfect skin regeneration. Science 276: 75-81, 1997.

50. Mirza R, DiPietro LA, and Koh TJ. Selective and specific macrophage ablation is detrimental to wound healing in mice. Am J Pathol 175: 2454-2462, 2009.

51. Mirza R and Koh TJ. Dysregulation of monocyte/macrophage phenotype in wounds of diabetic mice. Cytokine 56: 256-264, 2011.

52. Morelli E, Leone E, Cantafio ME, Di Martino MT, Amodio N, Biamonte L, Gulla A, Foresta U, Pitari MR, Botta C, Rossi M, Neri A, Munshi NC, Anderson KC, Tagliaferri P, and Tassone P. Selective targeting of IRF4 by synthetic microRNA-125b-5p mimics induces anti-multiple myeloma activity in vitro and in vivo. Leukemia 29: 21732183, 2015.

53. Mosser DM and Edwards JP. Exploring the full spectrum of macrophage activation. Nat Rev Immunol 8: 958-969, 2008.

54. Mullokandov G, Baccarini A, Ruzo A, Jayaprakash AD, Tung N, Israelow B, Evans MJ, Sachidanandam R, and Brown BD. High-throughput assessment of microRNA activity and function using microRNA sensor and decoy libraries. Nat Methods 9: 840-846, 2012. 
55. Murray PJ, Allen JE, Biswas SK, Fisher EA, Gilroy DW, Goerdt S, Gordon S, Hamilton JA, Ivashkiv LB, Lawrence T, Locati M, Mantovani A, Martinez FO, Mege JL, Mosser DM, Natoli G, Saeij JP, Schultze JL, Shirey KA, Sica A, Suttles J, Udalova I, van Ginderachter JA, Vogel SN, and Wynn TA. Macrophage activation and polarization: nomenclature and experimental guidelines. Immunity 41: 14-20, 2014.

56. Navarro A, Pairet S, Alvarez-Larran A, Pons A, Ferrer G, Longaron R, Fernandez-Rodriguez C, Camacho L, Monzo M, Besses C, and Bellosillo B. miR-203 and miR-221 regulate SOCS1 and SOCS3 in essential thrombocythemia. Blood Cancer J 6: e406, 2016.

57. Necsulea A and Kaessmann H. Evolutionary dynamics of coding and non-coding transcriptomes. Nat Rev Genet 15: 734-748, 2014.

58. O'Connell RM, Chaudhuri AA, Rao DS, Gibson WS, Balazs $\mathrm{AB}$, and Baltimore D. MicroRNAs enriched in hematopoietic stem cells differentially regulate long-term hematopoietic output. Proc Natl Acad Sci U S A 107: 14235-14240, 2010.

59. O'Connell RM, Taganov KD, Boldin MP, Cheng G, and Baltimore D. MicroRNA-155 is induced during the macrophage inflammatory response. Proc Natl Acad Sci U S A 104: 1604-1609, 2007.

60. O'Neill LA, Sheedy FJ, and McCoy CE. MicroRNAs: the fine-tuners of Toll-like receptor signalling. Nat Rev Immunol 11: 163-175, 2011.

61. Ouimet M, Ediriweera HN, Gundra UM, Sheedy FJ, Ramkhelawon B, Hutchison SB, Rinehold K, van Solingen C, Fullerton MD, Cecchini K, Rayner KJ, Steinberg GR, Zamore PD, Fisher EA, Loke P, and Moore KJ. MicroRNA-33-dependent regulation of macrophage metabolism directs immune cell polarization in atherosclerosis. J Clin Invest 125: 4334-4348, 2015.

62. Persson JL. miR-155 meets the JAK/STAT pathway. Cell Cycle 12: 2170, 2013.

63. Pizzolla A, Hultqvist M, Nilson B, Grimm MJ, Eneljung T, Jonsson IM, Verdrengh M, Kelkka T, Gjertsson I, Segal $\mathrm{BH}$, and Holmdahl R. Reactive oxygen species produced by the NADPH oxidase 2 complex in monocytes protect mice from bacterial infections. J Immunol 188: 5003-5011, 2012.

64. Pospisil V, Vargova K, Kokavec J, Rybarova J, Savvulidi F, Jonasova A, Necas E, Zavadil J, Laslo P, and Stopka T. Epigenetic silencing of the oncogenic miR-17-92 cluster during PU.1-directed macrophage differentiation. EMBO J 30: 4450-4464, 2011.

65. Ranjan R, Lee YG, Karpurapu M, Syed MA, Chung S, Deng J, Jeong JJ, Zhao G, Xiao L, Sadikot RT, Weiss MJ, Christman JW, and Park GY. p47phox and reactive oxygen species production modulate expression of microRNA-451 in macrophages. Free Radic Res 49: 25-34, 2015.

66. Raposo G and Stoorvogel W. Extracellular vesicles: exosomes, microvesicles, and friends. J Cell Biol 200: 373383, 2013.

67. Ravichandran KS and Lorenz U. Engulfment of apoptotic cells: signals for a good meal. Nat Rev Immunol 7: 964974, 2007.

68. Rodriguez-Vita $\mathbf{J}$ and Lawrence $\mathrm{T}$. The resolution of inflammation and cancer. Cytokine Growth Factor Rev 21: 61-65, 2010.

69. Rosa A, Ballarino M, Sorrentino A, Sthandier O, De Angelis FG, Marchioni M, Masella B, Guarini A, Fatica A, Peschle C, and Bozzoni I. The interplay between the master transcription factor PU.1 and miR-424 regulates human monocyte/macrophage differentiation. Proc Natl Acad Sci U S A 104: 19849-19854, 2007.

70. Roy S. Resolution of wound inflammation: significance of apoptotic cell phagocytosis. Adv Wound Care (New Rochelle) 2: 76-81, 2010.

71. Roy S and Sen CK. MiRNA in innate immune responses: novel players in wound inflammation. Physiol Genomics 43: 557-565, 2011.

72. Roy $\mathrm{S}$ and Sen CK. miRNA in wound inflammation and angiogenesis. Microcirculation 19: 224-232, 2012.

73. Saha B, Momen-Heravi F, Kodys K, and Szabo G. MicroRNA cargo of extracellular vesicles from alcohol-exposed monocytes signals naive monocytes to differentiate into M2 macrophages. J Biol Chem 291: 149-159, 2016.

74. Schwerk J and Savan R. Translating the untranslated region. J Immunol 195: 2963-2971, 2015.

75. Segal BH, Grimm MJ, Khan AN, Han W, and Blackwell TS. Regulation of innate immunity by NADPH oxidase. Free Radic Biol Med 53: 72-80, 2012.

76. Sen CK and Roy S. miRNA: licensed to kill the messenger. DNA Cell Biol 26: 193-194, 2007.

77. Sen CK and Roy S. Redox signals in wound healing. Biochim Biophys Acta 1780: 1348-1361, 2008.

78. Sen CK and Roy S. MicroRNA 21 in tissue injury and inflammation. Cardiovasc Res 96: 230-233, 2012.

79. Shilo S, Roy S, Khanna S, and Sen CK. MicroRNA in cutaneous wound healing: a new paradigm. DNA Cell Biol 26: 227-237, 2007.

80. Shilo S, Roy S, Khanna S, and Sen CK. Evidence for the involvement of miRNA in redox regulated angiogenic response of human microvascular endothelial cells. Arterioscler Thromb Vasc Biol 28: 471-477, 2008.

81. Simone NL, Soule BP, Ly D, Saleh AD, Savage JE, Degraff W, Cook J, Harris CC, Gius D, and Mitchell JB. Ionizing radiation-induced oxidative stress alters miRNA expression. PLoS One 4: e6377, 2009.

82. Squadrito ML, Etzrodt M, De Palma M, and Pittet MJ. MicroRNA-mediated control of macrophages and its implications for cancer. Trends Immunol 34: 350-359, 2013.

83. Squadrito ML, Pucci F, Magri L, Moi D, Gilfillan GD, Ranghetti A, Casazza A, Mazzone M, Lyle R, Naldini L, and De Palma M. miR-511-3p modulates genetic programs of tumorassociated macrophages. Cell Rep 1: 141-154, 2012.

84. Taganov KD, Boldin MP, Chang KJ, and Baltimore D. NFkappaB-dependent induction of microRNA miR-146, an inhibitor targeted to signaling proteins of innate immune responses. Proc Natl Acad Sci U S A 103: 12481-12486, 2006.

85. Thery C, Ostrowski M, and Segura E. Membrane vesicles as conveyors of immune responses. Nat Rev Immunol 9: 581-593, 2009.

86. Tu K, Zheng X, Dou C, Li C, Yang W, Yao Y, and Liu Q. MicroRNA-130b promotes cell aggressiveness by inhibiting peroxisome proliferator-activated receptor gamma in human hepatocellular carcinoma. Int J Mol Sci 15: 2048620499, 2014.

87. Underhill DM. Collaboration between the innate immune receptors dectin-1, TLRs, and Nods. Immunol Rev 219: 75-87, 2007.

88. van Furth $\mathrm{R}$ and Cohn ZA. The origin and kinetics of mononuclear phagocytes. J Exp Med 128: 415-435, 1968.

89. Velu CS, Baktula AM, and Grimes HL. Gfi1 regulates miR-21 and miR-196b to control myelopoiesis. Blood 113: 4720 4728, 2009. 
90. Wang S, Zhang X, Ju Y, Zhao B, Yan X, Hu J, Shi L, Yang L, Ma Z, Chen L, Liu Y, Duan Z, Chen X, and Meng S. MicroRNA-146a feedback suppresses $T$ cell immune function by targeting Stat 1 in patients with chronic hepatitis B. J Immunol 191: 293-301, 2013.

91. Wilson A, Oser GM, Jaworski M, Blanco-Bose WE, Laurenti E, Adolphe C, Essers MA, Macdonald HR, and Trumpp A. Dormant and self-renewing hematopoietic stem cells and their niches. Ann N Y Acad Sci 1106: 64-75, 2007.

92. Wu W, Takanashi M, Borjigin N, Ohno SI, Fujita K, Hoshino S, Osaka Y, Tsuchida A, and Kuroda M. MicroRNA-18a modulates STAT3 activity through negative regulation of PIAS3 during gastric adenocarcinogenesis. Br J Cancer 108: 653-661, 2013.

93. Xu J, Wu W, Zhang L, Dorset-Martin W, Morris MW, Mitchell ME, and Liechty KW. The role of MicroRNA$146 \mathrm{a}$ in the pathogenesis of the diabetic wound-healing impairment: correction with mesenchymal stem cell treatment. Diabetes 61: 2906-2912, 2012.

94. Yamazaki M, Maruyama S, Abe T, Essa A, Babkair H, Cheng J, and Saku T. MFG-E8 expression for progression of oral squamous cell carcinoma and for self-clearance of apoptotic cells. Lab Invest 94: 1260-1272, 2014.

95. Yanez-Mo M, Siljander PR, Andreu Z, Zavec AB, Borras FE, Buzas EI, Buzas K, Casal E, Cappello F, Carvalho J, Colas E, Cordeiro-da Silva A, Fais S, Falcon-Perez JM, Ghobrial IM, Giebel B, Gimona M, Graner M, Gursel I, Gursel M, Heegaard NH, Hendrix A, Kierulf P, Kokubun K, Kosanovic M, KraljIglic V, Kramer-Albers EM, Laitinen S, Lasser C, Lener T, Ligeti E, Line A, Lipps G, Llorente A, Lotvall J, MancekKeber M, Marcilla A, Mittelbrunn M, Nazarenko I, Nolte-'t Hoen EN, Nyman TA, O'Driscoll L, Olivan M, Oliveira C, Pallinger E, Del Portillo HA, Reventos J, Rigau M, Rohde E, Sammar M, Sanchez-Madrid F, Santarem N, Schallmoser K, Ostenfeld MS, Stoorvogel W, Stukelj R, Van der Grein SG, Vasconcelos MH, Wauben MH, and De Wever O. Biological properties of extracellular vesicles and their physiological functions. J Extracell Vesicles 4: 27066, 2015.

96. Yoon WH, Meinhardt $\mathrm{H}$, and Montell DJ. miRNAmediated feedback inhibition of JAK/STAT morphogen signalling establishes a cell fate threshold. Nat Cell Biol 13: 1062-1069, 2011.
Address correspondence to: Dr. Sashwati Roy Department of Surgery

Davis Heart and Lung Research Institute Center for Regenerative Medicine and Cell Based Therapies and Comprehensive Wound Center

The Ohio State University Wexner Medical Center 473 West 12th Avenue, 511 DHLRI

Columbus, OH 43210

E-mail: sashwati.roy@osumc.edu

Date of first submission to ARS Central, June 16, 2016; date of acceptance, June 28, 2016.

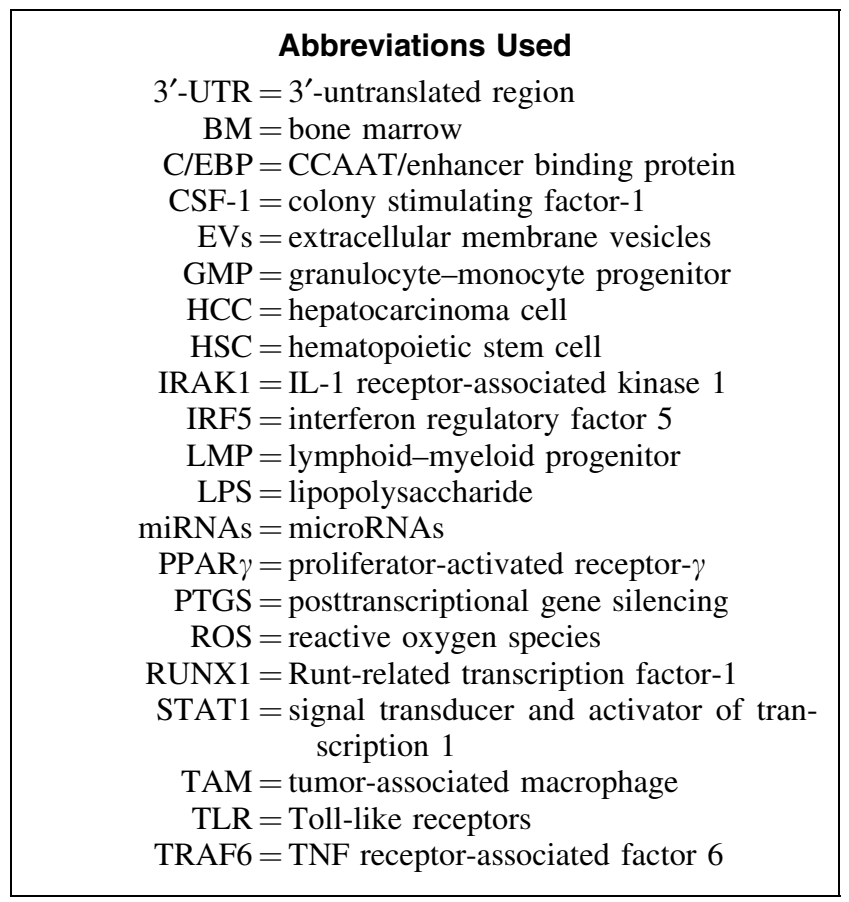

